\title{
Intraperitoneal Perfusion Therapy of Endostar Combined with Platinum Chemotherapy for Malignant Serous Effusions: A Meta-analysis
}

\author{
Rong Liang ${ }^{\star}$, Hai-Ying Xie ${ }^{\star}$, Yan Lin, Qian Li, Chun-Ling Yuan, Zhi-Hui Liu, \\ Yong-Qiang $\mathrm{Li}^{*}$
}

\begin{abstract}
Background: Malignant serous effusions (MSE) are one complication in patients with advanced cancer. Endostar is a new anti-tumor drug targeting vessels which exerts potent inhibition of neovascularization. This study aimed to systematically evaluate the efficacy and safety of intraperitoneal perfusion therapy of Endostar combined with platinum chemotherapy for malignant serous effusions (MSE). Materials and Methods: Randomized controlled trials (RCTs) on intraperitoneal perfusion therapy of Endostar combined with platinum chemotherapy for malignant serous effusions were searched in the electronic data of PubMed, EMBASE, Web of Science, CNKI, VIP, CBM and WanFang. The quality of RCTs was evaluated by two independent researchers and a meta-analysis was performed using RevMan 5.3 software. Results: The total of 25 RCTs included in the meta-analysis covered 1,253 patients, and all literature quality was evaluated as " $B$ " grade. The meta-analysis showed that Endostar combined with platinum had an advantage over platinum alone in terms of response rate of effusions $(76 \%$ vs $48 \%, R R=1.63,95 \% \mathrm{CI}: 1.50-1.78, P<0.00001)$ and improvement rate in quality of life $(69 \%$ vs $44 \%, \mathrm{RR}=1.57,95 \%$ CI: $1.42-1.74, P<0.00001)$. As for safety, there was no significant difference between the two groups in the incidences of nausea and vomiting $(35 \%$ vs $34 \%, \mathrm{RR}=1.01,95 \% \mathrm{CI}: 0.87-1.18, P=0.88)$, leucopenia $(38 \%$ vs $38 \%$, RR=1, 95\% CI: $0.87-1.15, P=0.99)$, and renal impairment $(18 \%$ vs $20 \%, R R=0.86$, 95\% CI: 0.43-1.74, $P=0.68)$. Conclusions: Endostar combined with platinum by intraperitoneal perfusion is effective for malignant serous effusions, and patient quality of life is significantly improved without the incidence of adverse reactions being obviously increased.
\end{abstract}

Keywords: Endostar - malignant serous effusions - meta-analysis - randomized controlled trials

Asian Pac J Cancer Prev, 16 (18), 8637-8644

\section{Introduction}

Malignant serous effusions (MSE) are one of the common complications in patients with advanced cancer, with serious impact on systemic antitumor treatment and quality of life, suggesting a poor prognosis for patients. Currently there are no standard treatment patterns or reference guide for malignant serous effusions (Barni et al., 2001), making treatment a difficult task. Usually treatment strategy of MSE is to perform cavity puncture for drainage of the fluid and perfuse into the cavity with drugs to inhibit MSE generation, but the overall effect is poor. Many studies have confirmed that vascular endothelial growth factor (VEGF) and matrix metalloproteinase (MMPs) are two important factors that are involved in the formation of MSE. Compared with benign effusions, VEGF was significantly increased in MSE (Verheul et al., 2000; Zhou et al., 2009), in which MMPs can also result in ascites formation by promoting
VEGF release (Becker et al., 2006; Tamsma, 2007), the research progress in above mechanism prompted antiVEGF become a new therapeutic strategy for MSE. Study found that intraperitoneal perfusion of bevacizumab (A kind of anti-VEGF humanized monoclonal antibody) shows curative effect either as monotherapy or combined with other chemotherapeutic drugs (Kobold et al., 2009). However, because bevacizumab is an expensive imported targeted drug with difficult clinical application, it is necessary to seek more economical and effective antiVEGF alternative drugs.

Endostar (Chemical name: recombinant human endostatin) is a new anti-tumor drug targeting to vessels developed by China. Endostar shows potent inhibition on neovascularization (Liu et al., 2015), and its mechanisms are associated with decreasing the expression of VEGFR-2, MMPs, TGF- $\beta 1$, HIF- $1 \alpha$ and bFGF (Ling et al., 2007; Lu et al., 2008; Wu et al., 2014). When combined with cisplatin, Endostar showed 
enhanced anti-cancer effect in esophageal cancer and lung cancer (Xu et al., 2014; Fan et al., 2015). Furthermore, Endostar inhibits ascites formation and prolongs survival in malignant ascites mouse models (Wei et al., 2015) and acquired 45\% 100\% effective rates in MSE patients when Endostar was admmonistrated through intraperitoneal perfusion combined with platinum (Yan et al., 2012). However, the related studies are single center RCTs with small sample size, and among each study, the treatment programs were confused and had no reference standard and consistent observation index. This study aims to perform a meta-analysis to evaluate effectiveness and safety of intraperitoneal perfusion of Endostar combined with platinum in malignant serous effusions.

\section{Materials and Methods}

\section{Inclusion criteria of literature}

The literatures selected for inclusion met the following criteria: published randomized controlled trial of Endostar combined with platinum intraperitoneal perfusion therapy in malignant serous effusions. The experimental group received Endostar plus platinum and control group received platinum alone. No chemotherapy, radiation or interventional therapy was performed simultaneously. The full text provided effective and safety indicators such as objective response rate [complete response (CR) + partial response (PR)], Karnofsky performance status (KPS) (behavioral state) score, adverse reactions and other outcome indicators.

\section{Exclusion criteria of literature}

Exclusion criteria were as follows (1) Review, case reports, animal experiments and basic research; (2) Subject information was not complete; (3) Repeated reports; (4) Non-random studies without control group.

\section{Literature search}

An electronic search was performed on scientific literature published in the databases of PubMed, EMBASE, web of science, Wanfang, CNKI, VIP and CBM. Meanwhile, manually search was performed on reference literatures of reviews. The search was performed using the following English retrieval words: Endostar; recombinant human endostatin; hydrothorax; ascites; pericardial effusion; pleural effusion; peritoneal effusion; serous effusion. The retrieval time was up to December $8,2014$.

\section{Data extraction and quality evaluation}

The quality of included literature was evaluated using Risk of bias evaluation criteria of Cochrane Handbook for systematic reviews of interventions (Version 5.3), and the detailed content was as follows: (1) Random allocation scheme; (2) Allocation concealment; (3) Blind method; (4) The data integrity; (5) There was no selective reporting of results; (6) Other sources of bias. The quality evaluation was carried out independently by two researchers, and disagreement between the reviewers was settled by discussion. The entries are divided into three grades: full, unclear and incomplete. There were 6 "full" in entries was classified as "A" grade, there were 1 or more "unclear" was classified as "B" grade, and there are 1 or more "incomplete" was classified as "C" grade.

\section{Statistical analysis}

Meta-analysis was performed using RevMan 5.3 software provided by Cochrane collaboration network. If homogeneity exist among studies then fixed-effect model was applied. If there is obvious inter-study heterogeneity, random-effect model was applied to analyze the sources of heterogeneity and to judge the publication bias through the funnel plot. The pooled effects of this study were expressed using RR and 95\% confidence interval (CI). $P<0.05$ was considered the statistically significant difference.

\section{Results}

\section{Literature selection}

A total of 535 literatures were identified by first screening. Firstly, through extensive reading the title and abstract, reviews, case reports, duplicated reports, animal experiments, and papers with the irrelevant subject or without conformity to the inclusion criteria were excluded, with 58 remaining literatures. After careful reading of the text, 33 literatures were further excluded, including non randomized trials, studies without control group, patients with systemic chemotherapy and intervention measures inconsistent with criteria. Eventually, 25 RCTs remained for meta-analysis, including 1523 patients, with 749 cases in the experimental group and 774 cases in the control group. The flow chart of literature screening process is shown in Figure 1, and the basic characteristics of the study are shown in Table 1.

\section{Methodological quality assessment of the study}

All studies referred to the random grouping, data integrity, the non-selective reporting. Among all 25 studies, 8 studies described using a random number table for grouping, 4 studies using random digit grouping method, 1 study by envelope method, and other 12 studies did not describe the detailed grouping methods. All studies did not describe the implementation of the blind method, and other sources of bias were not clear. The quality of all

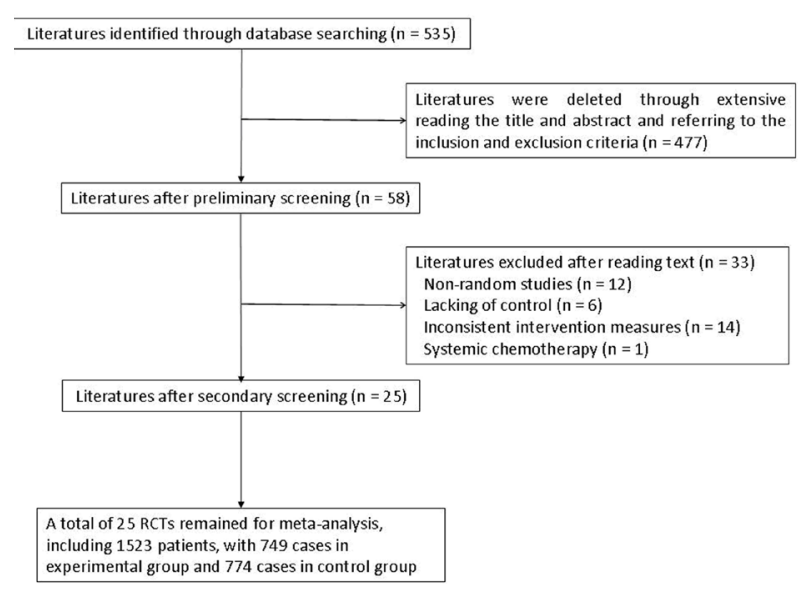

Figure 1. Flow Chart of Literature Search. RCTs, Randomized Controlled Trials 
Table 1. General Characteristics of Included Clinical Trials

\begin{tabular}{|c|c|c|c|c|c|c|c|}
\hline Studies & $\begin{array}{c}\text { Effusion } \\
\text { type }\end{array}$ & Tumor type & $\begin{array}{l}\text { Cases } \\
(\mathrm{T} / \mathrm{C}) \\
\end{array}$ & Endostar & Chemotherapy & Duration & $\begin{array}{c}\begin{array}{c}\text { Outcome } \\
\text { measure }\end{array} \\
\end{array}$ \\
\hline Zhao et al., 2014 & $\begin{array}{l}\text { Pleural and } \\
\text { peritoneal }\end{array}$ & $\begin{array}{l}\text { Multiple } \\
\text { cancers }\end{array}$ & $23 / 22$ & 45 or $60 \mathrm{mg} / \mathrm{w}$ & $\begin{array}{c}\text { Cisplatin } 40 \mathrm{mg} \text { or } \\
60 \mathrm{mg} / \mathrm{w}\end{array}$ & $\geq 4 \mathrm{~W}$ & $\begin{array}{c}1,2,3 \\
4,5\end{array}$ \\
\hline Yue et al., 2014 & Pleural & $\begin{array}{l}\text { Lung } \\
\text { cancer }\end{array}$ & $43 / 43$ & $60 \mathrm{mg} / \mathrm{w}$ & Cisplatin $60 \mathrm{mg} / \mathrm{w}$ & $2-3 W$ & $1,2,3,4$, \\
\hline Lu, 2014 & Pleural & $\begin{array}{l}\text { Lung } \\
\text { cancer }\end{array}$ & $30 / 30$ & $45 \mathrm{mg} / \mathrm{w}$ & Cisplatin $100 \mathrm{mg} / \mathrm{w}$ & $2 \mathrm{~W}$ & $1,3,4$ \\
\hline Huang, 2014 & Pleural & $\begin{array}{l}\text { Lung } \\
\text { cancer }\end{array}$ & $25 / 25$ & $60 \mathrm{mg} / \mathrm{w}$ & Cisplatin 50mg/w & - & $1,3,4,5$, \\
\hline Xiao et al., 2014 & peritoneal & $\begin{array}{l}\text { Multiple } \\
\text { cancers }\end{array}$ & $35 / 41$ & $\begin{array}{l}60 \mathrm{mg} / \mathrm{time}, \\
\text { interval 3d }\end{array}$ & $\begin{array}{l}\text { Cisplatin 40mg/ } \\
\text { time, interval } 3 \mathrm{~d}\end{array}$ & 6 times & $1,3,4,5$, \\
\hline Zhen et al., 2013 & Pleural & $\begin{array}{l}\text { Multiple } \\
\text { cancers }\end{array}$ & $60 / 60$ & $\begin{array}{l}90 \mathrm{mg} / \mathrm{time}, \\
\text { interval 3d }\end{array}$ & $\begin{array}{l}\text { Cisplatin } 30-40 \mathrm{mg} / \\
\text { time, interval } 21 \mathrm{~d}\end{array}$ & $1-4$ cycle & $1,3,4$ \\
\hline Yang Y et al., 2013 & Pleural & $\begin{array}{l}\text { Lung } \\
\text { cancer }\end{array}$ & $21 / 21$ & $60 \mathrm{mg} / \mathrm{w}$ & Cisplatin 40mg/w & $3 \mathrm{~W}$ & $1,3,4,5$, \\
\hline Yang K, 2013 & Pleural & $\begin{array}{l}\text { Lung } \\
\text { cancer }\end{array}$ & $28 / 28$ & $\begin{array}{l}7.5 \mathrm{mg} / \mathrm{m} 2 / \\
\text { time,d1,7,14 }\end{array}$ & $\begin{array}{c}\text { Nedaplatin } \\
100 \mathrm{mg} / \mathrm{d}, \mathrm{d} 1,7,14\end{array}$ & 2 cycle & $1,4,5$ \\
\hline Kang et al., 2013 & Pleural & $\begin{array}{l}\text { Multiple } \\
\text { cancers }\end{array}$ & $30 / 30$ & $\begin{array}{l}45 \mathrm{mg} / \mathrm{d} \\
\mathrm{d} 1,4,7\end{array}$ & $\begin{array}{c}\text { Cisplatin } 40 \mathrm{mg} / \mathrm{d} \text {, } \\
\mathrm{d} 2,5,8\end{array}$ & 1 cycle & $1,4,5$ \\
\hline Hang et al., 2013 & Pleural & $\begin{array}{l}\text { Multiple } \\
\text { cancers }\end{array}$ & $20 / 20$ & $\begin{array}{l}\text { 30mg/time, } \\
\text { interval 3d }\end{array}$ & $\begin{array}{l}\text { Cisplatin } 20-60 \mathrm{mg} / \\
\mathrm{m} 2 / \text { time, interval } \\
3 \mathrm{~d}\end{array}$ & $1-3$ times & 1,4, \\
\hline Yao et al., 2012 & Pleural & $\begin{array}{l}\text { Multiple } \\
\text { cancers }\end{array}$ & $30 / 30$ & $45 \mathrm{mg} /$ time & $\begin{array}{l}\text { Nedaplatin } 40 \mathrm{mg} / \\
\text { time }\end{array}$ & - & $1,3,4$ \\
\hline Xue, 2012 & $\begin{array}{l}\text { Pleural and } \\
\text { peritoneal }\end{array}$ & - & $28 / 28$ & $30 \mathrm{mg} / \mathrm{w}$ & $\begin{array}{l}\text { Cisplatin 40mg/ } \\
\mathrm{m} 2 / \mathrm{W}\end{array}$ & $\begin{array}{l}\text { At least } \\
6 \mathrm{~W}\end{array}$ & 1 , \\
\hline Shen et al., 2012 & Pleural & $\begin{array}{l}\text { Lung } \\
\text { cancer }\end{array}$ & $40 / 40$ & $60 \mathrm{mg} / \mathrm{w}$ & Cisplatin 40mg/W & $3 \mathrm{~W}$ & $1,3,4$ \\
\hline Miao and Kong, 2012 & Pleural & $\begin{array}{l}\text { Lung } \\
\text { cancer }\end{array}$ & $24 / 24$ & $45-60 \mathrm{mg} / \mathrm{w}$ & $\begin{array}{l}\text { Cisplatin 40mg/ } \\
\mathrm{m} 2 / \mathrm{W}\end{array}$ & $3 \mathrm{~W}$ & 1 , \\
\hline Liu and Wang, 2012 & Pleural & $\begin{array}{l}\text { Lung } \\
\text { cancer }\end{array}$ & $30 / 30$ & $120 \mathrm{mg} / \mathrm{w}$ & Cisplatin $120 \mathrm{mg} / \mathrm{W}$ & - & $1,3,4,5$, \\
\hline Jiang, 2012 & Pleural & $\begin{array}{l}\text { Lung } \\
\text { cancer }\end{array}$ & $30 / 30$ & $30 \mathrm{mg} / \mathrm{w}$ & $\begin{array}{l}\text { Cisplatin 60mg/ } \\
\mathrm{m} 2 / \mathrm{W}\end{array}$ & $2 \mathrm{~W}$ & $1,3,4$ \\
\hline Zhen et al., 2011 & $\begin{array}{c}\text { Pleural and } \\
\text { peritoneal }\end{array}$ & $\begin{array}{l}\text { Multiple } \\
\text { cancers }\end{array}$ & $25 / 25$ & $60 \mathrm{mg} / \mathrm{m} 2 / \mathrm{w}$ & $\begin{array}{l}\text { Cisplatin 60mg/ } \\
\mathrm{m} 2 / \mathrm{W}\end{array}$ & $1-2 \mathrm{~W}$ & 1, \\
\hline Mao et al., 2011 & Pleural & $\begin{array}{l}\text { Multiple } \\
\text { cancers }\end{array}$ & $45 / 45$ & $60 \mathrm{mg} / \mathrm{w}$ & $\begin{array}{l}\text { Cisplatin 40mg/ } \\
\mathrm{m} 2 / \mathrm{W}\end{array}$ & $2 \mathrm{~W}$ & 1 , \\
\hline Li, 2011 & Pleural & $\begin{array}{l}\text { Lung } \\
\text { cancer }\end{array}$ & $21 / 21$ & $45 \mathrm{mg} / \mathrm{w}$ & $\begin{array}{l}\text { Cisplatin 60mg/ } \\
\mathrm{m} 2 / \mathrm{W}\end{array}$ & $3 \mathrm{~W}$ & 1 , \\
\hline Hang et al., 2011 & $\begin{array}{l}\text { Serous } \\
\text { cavity }\end{array}$ & $\begin{array}{l}\text { Multiple } \\
\text { cancers }\end{array}$ & $23 / 36$ & $\begin{array}{l}\text { 30-60mg/ } \\
\text { time }\end{array}$ & $\begin{array}{l}\text { Cisplatin } 20-80 \mathrm{mg} / \\
\text { time }\end{array}$ & $2 \mathrm{~W}$ & 1, \\
\hline Fei and Yang, 2011 & $\begin{array}{c}\text { Pleural and } \\
\text { peritoneal }\end{array}$ & $\begin{array}{l}\text { Multiple } \\
\text { cancers }\end{array}$ & $32 / 38$ & $60 \mathrm{mg} / \mathrm{w}$ & Cisplatin 40mg/W & $2 \mathrm{~W}$ & $1,3,4$ \\
\hline Liu et al., 2011 & Pleural & $\begin{array}{l}\text { Lung } \\
\text { cancer }\end{array}$ & $23 / 23$ & $45 \mathrm{mg} / \mathrm{w}$ & $\begin{array}{l}\text { Carboplatin } \\
400 \mathrm{mg} / \mathrm{W}\end{array}$ & $4 \mathrm{~W}$ & 1,4 \\
\hline Li W et al., 2010 & Pleural & $\begin{array}{l}\text { Lung } \\
\text { cancer }\end{array}$ & $32 / 32$ & $30 \mathrm{mg} / \mathrm{w}$ & $\begin{array}{l}\text { Cisplatin 40mg/ } \\
\mathrm{m} 2 / \mathrm{W}\end{array}$ & $3 \mathrm{~W}$ & 1, \\
\hline Li JP et al., 2010 & Pleural & - & $33 / 34$ & $30 \mathrm{mg} / \mathrm{w}$ & $\begin{array}{l}\text { Cisplatin 40mg/ } \\
\text { m2/W }\end{array}$ & $3 \mathrm{~W}$ & $1,4,5$ \\
\hline Huang, 2010 & Pleural & $\begin{array}{l}\text { Lung } \\
\text { cancer }\end{array}$ & $18 / 18$ & $45 \mathrm{mg} / \mathrm{w}$ & $\begin{array}{l}\text { Cisplatin } 60 \mathrm{mg} / \\
\mathrm{m} 2 / \mathrm{W}\end{array}$ & $3 \mathrm{~W}$ & $1,2,3$ \\
\hline
\end{tabular}


Rong Liang et al

the literatures was strictly evaluated as "B" grade, with the moderate risk of bias (Table 2).

\section{Meta-analysis}

Response rate of effusions: Meta-analysis was carried out using fixed-effect model and showed no statistical heterogeneity $\left(P=0.96, \mathrm{I}_{2}=0 \%\right)$ between the 25 studies.

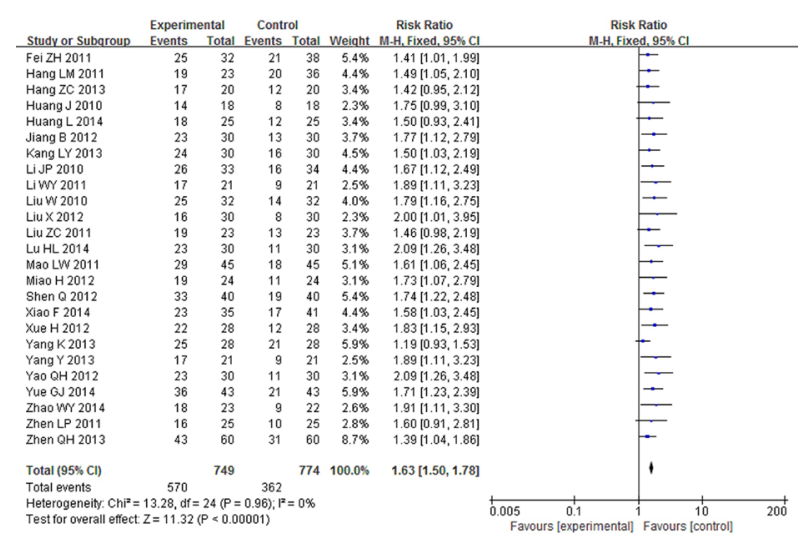

Figure 2. Forest Plot for Comparison of Response Rate in Endostar Combined with Platinum Versus Platinum Alone for Treating MSE. MSE, Malignant Serous Effusions
The results showed that the difference in response rates was statistically significant difference between Endostar combined with platinum group and platinum alone group (76\% vs. $47 \%, \mathrm{RR}=1.63,95 \% \mathrm{CI}: 1.50-1.78, P<0.00001$ ) (Figure 2).

Life quality improvement rate: There were no statistical heterogeneity $\left(P=0.8, \mathrm{I}_{2}=0 \%\right)$ among 18 studies by meta-analysis using fixed-effect model. The results showed that the difference in life quality improvement rate between the two groups was statistically significant

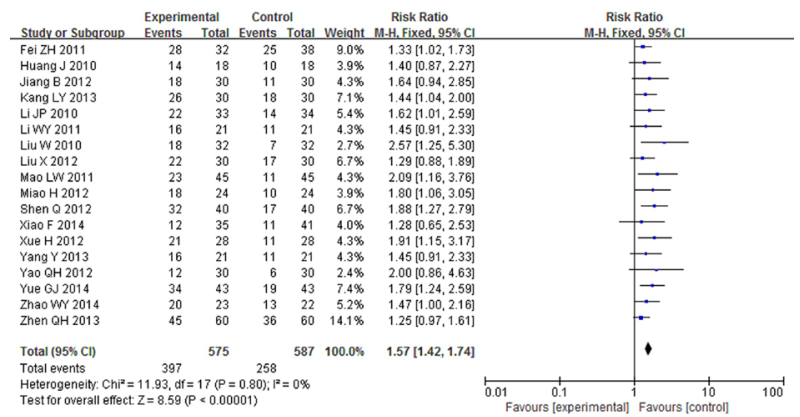

Figure 3. Forest Plot for Comparison of Life Quality Improvement Rate in Endostar Combined with Platinum Versus Platinum Alone for Treating MSE. MSE, Malignant Serous Effusions

Table 2. Methodological Quality Assessment Included in Studies

\begin{tabular}{|c|c|c|c|c|c|c|}
\hline Studies & Random method & $\begin{array}{c}\text { Allocation } \\
\text { concealment }\end{array}$ & Blind & Outcome data & $\begin{array}{l}\text { Selective } \\
\text { outcome }\end{array}$ & $\begin{array}{c}\text { Other sources } \\
\text { of bias }\end{array}$ \\
\hline Zhao et al., 2014 & Unclear & Unclear & Unclear & Integrity & No & Unclear \\
\hline Yue et al., 2014 & Random number & Unclear & Unclear & Integrity & No & Unclear \\
\hline Lu, 2014 & Random number table & Unclear & Unclear & Integrity & No & Unclear \\
\hline Huang, 2014 & Unclear & Unclear & Unclear & Integrity & No & Unclear \\
\hline Xiao et al., 2014 & Random number & Unclear & Unclear & Integrity & No & Unclear \\
\hline Zhen et al., 2013 & Unclear & Unclear & Unclear & Integrity & No & Unclear \\
\hline Yang Y et al., 2013 & Random number & Unclear & Unclear & Integrity & No & Unclear \\
\hline Yang K, 2013 & Unclear & Unclear & Unclear & Integrity & No & Unclear \\
\hline Kang et al., 2013 & Random number & Unclear & Unclear & Integrity & No & Unclear \\
\hline Hang et al., 2013 & Unclear & Unclear & Unclear & Integrity & No & Unclear \\
\hline Yao et al., 2012 & Random number table & Unclear & Unclear & Integrity & No & Unclear \\
\hline Xue, 2012 & Random number table & Unclear & Unclear & Integrity & No & Unclear \\
\hline Shen et al., 2012 & Random number & Unclear & Unclear & Integrity & No & Unclear \\
\hline Miao and Kong, 2012 & Unclear & Unclear & Unclear & Integrity & No & Unclear \\
\hline Liu and Wang, 2012 & Unclear & Unclear & Unclear & Integrity & No & Unclear \\
\hline Jiang, 2012 & Random number table & Unclear & Unclear & Integrity & No & Unclear \\
\hline Zhen et al., 2011) & Unclear & Unclear & Unclear & Integrity & No & Unclear \\
\hline Mao et al., 2011 & Random number & Unclear & Unclear & Integrity & No & Unclear \\
\hline $\mathrm{Li}, 2011$ & Random number table & Unclear & Unclear & Integrity & No & Unclear \\
\hline Hang et al., 2011 & Unclear & Unclear & Unclear & Integrity & No & Unclear \\
\hline Fei and Yang, 2011 & Unclear & Unclear & Unclear & Integrity & No & Unclear \\
\hline Liu et al., 2011 & Unclear & Unclear & Unclear & Integrity & No & Unclear \\
\hline Li W et al., 2010 & Unclear & Unclear & Unclear & Integrity & No & Unclear \\
\hline Li JP et al., 2010 & Random number table & Unclear & Unclear & Integrity & No & Unclear \\
\hline Huang, 2010 & Random number table & Unclear & Unclear & Integrity & No & Unclear \\
\hline
\end{tabular}


(69\% vs. 44\%, RR=1.57, 95\% CI: 1.42-1.74) (Figure 3).

Rate of adverse effects: Meta-analysis using the fixed-effect model showed that 16 studies reported the occurrence of nausea and vomiting, with no statistically heterogeneity among results of different studies $(P=0.9$, $I_{2}=0 \%$ ). The results showed that the difference in nausea and vomiting between the two groups was not statistically significant (35\% vs. $34 \%, \mathrm{RR}=1.01,95 \% \mathrm{CI}: 0.87-1.18$, $P=0.88$ ) (Figure 4).

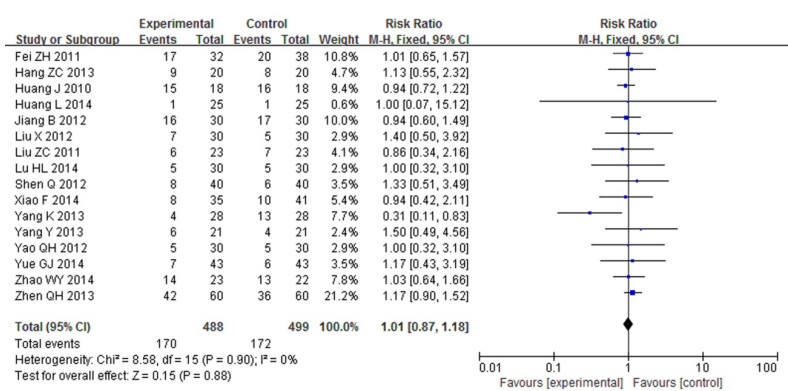

Figure 4. Forest Plot for Comparison of Nausea and Vomitting Reaction Rate in Endostar Combined with Platinum Versus Platinum Alone for Treating MSE. MSE, Malignant Serous Effusions

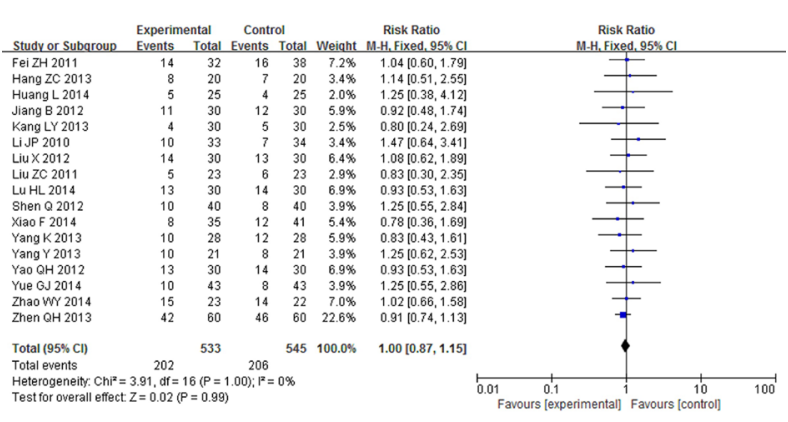

Figure 5. Forest Plot for Comparison of Leukopenia Rate in Endostar Combined with Platinum Versus Platinum Alone for Treating MSE. MSE, Malignant Serous Effusions
There were 17 studies which reported the occurrence of leukopenia, with no statistically heterogeneity among results of different studies $\left(P=1, \mathrm{I}_{2}=0 \%\right)$. The results showed that the difference in leucopenia between the two groups was not statistically significant (38\% vs.38\%, $\mathrm{RR}=1$, 95\%CI: 0.87-1.15, $P=0.99$ ) (Figure 5).

There were 4 studies which reported occurrence of renal damage, and the damage extent was I - II degree. There was no statistically heterogeneity among different studies. ( $\mathrm{I}_{2}=0 \%, P=0.92$ ). Meta-analysis was performed using fixed-effect model, and showed that the difference in renal damage between the two groups was not statistically significant $(18 \%$ vs. $20 \%, \mathrm{RR}=0.86,95 \% \mathrm{CI}: 0.43-1.74$, $P=0.68$ ) (Figure 6).

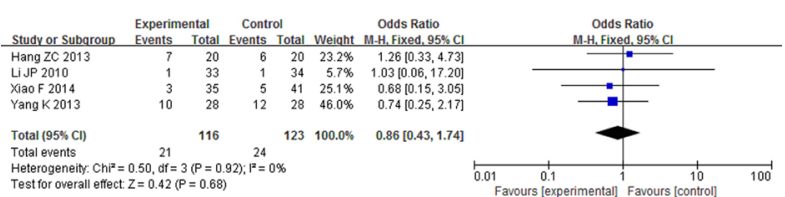

Figure 6. Forest Plot for Comparison of Renal Impairment Rate in Endostar Combined with Platinum Versus Platinum Alone for Treating MSE

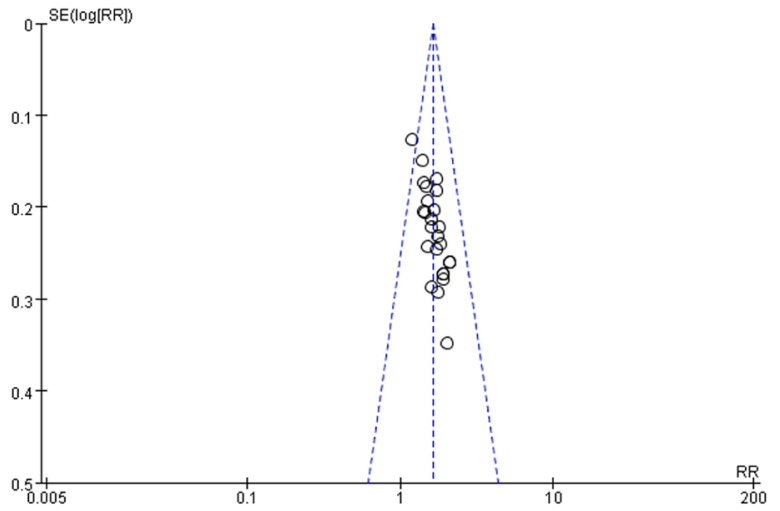

Figure 7. Funnel Plot for Comparison of Response Rate in the Endostar and Control Groups

Table 3. The Results of Response Rate Subgroup Analysis Summery Statistics

\begin{tabular}{|c|c|c|c|c|c|c|c|c|}
\hline \multirow[t]{2}{*}{ Subgroup } & \multirow[t]{2}{*}{ Literature number } & \multicolumn{2}{|c|}{ Heterogeneity test } & \multirow[t]{2}{*}{ RR value } & \multicolumn{2}{|c|}{ Response rate } & \multicolumn{2}{|c|}{$95 \% \mathrm{CI}$} \\
\hline & & $\mathrm{I}_{2}$ & $P$ value & & $\begin{array}{l}\text { Experiment } \\
\text { group }\end{array}$ & $\begin{array}{l}\text { Control } \\
\text { group }\end{array}$ & $\begin{array}{l}\text { Lower } \\
\text { limit }\end{array}$ & $\begin{array}{l}\text { Upper } \\
\text { limit }\end{array}$ \\
\hline \multicolumn{9}{|l|}{ Endostar dose } \\
\hline $30 \mathrm{mg} / \mathrm{w}$ & 5 & $0 \%$ & 0.91 & 1.7 & $79 \%$ & $47 \%$ & 1.4 & 2.06 \\
\hline $45 \mathrm{mg} / \mathrm{w}$ & 6 & $0 \%$ & 0.78 & 1.76 & $79 \%$ & $45 \%$ & 1.45 & 2.14 \\
\hline $60 \mathrm{mg} / \mathrm{w}$ & 8 & $0 \%$ & 0.99 & 1.62 & $74 \%$ & $46 \%$ & 1.4 & 1.88 \\
\hline$\geq 90 \mathrm{mg} / \mathrm{w}$ & 2 & $0 \%$ & 0.32 & 1.51 & $66 \%$ & $43 \%$ & 1.15 & 1.99 \\
\hline \multicolumn{9}{|c|}{ Endostar interval } \\
\hline $3 \mathrm{~d}$ & 3 & $0 \%$ & 0.93 & 1.51 & $75 \%$ & $49 \%$ & 1.19 & 1.91 \\
\hline $1 \mathrm{~W}$ & 19 & $0 \%$ & 0.9 & 1.67 & $76 \%$ & $46 \%$ & 1.51 & 1.85 \\
\hline $21 \mathrm{~d}$ & 1 & - & - & - & $72 \%$ & $52 \%$ & - & - \\
\hline \multicolumn{9}{|c|}{ Endostar duration } \\
\hline$\leq 2 \mathrm{~W}$ & 6 & $0 \%$ & 0.86 & 1.58 & $74 \%$ & $47 \%$ & 1.33 & 1.88 \\
\hline$>2 \mathrm{~W}$ & 13 & $0 \%$ & 0.62 & 1.61 & $79 \%$ & $49 \%$ & 1.44 & 1.81 \\
\hline \multicolumn{9}{|l|}{ Platinum drugs } \\
\hline Cisplatin & 22 & $0 \%$ & 1 & 1.65 & $75 \%$ & $46 \%$ & 1.51 & 1.81 \\
\hline Nedaplatin & 2 & $80 \%$ & 0.03 & 1.52 & $83 \%$ & $55 \%$ & 0.82 & 2.85 \\
\hline Carboplatin & 1 & - & - & - & $83 \%$ & $57 \%$ & - & - \\
\hline
\end{tabular}

Note: RR, relative risk. “-” indicates index which did not describe in studies. d: days. W: week. CI, confidence interval 
Subgroup analysis of response rate: Subgroup analysis on control rate of effusions showed that Endostar at dose of $45 \mathrm{mg} /$ times $(\mathrm{RR}=1.76)$, treatment interval of 7 days $(R R=1.67)$, treatment duration $\leq 2$ weeks $(R R=1.58)$, treatment duration $>2$ weeks $(R R=1.61)$, combined cisplatin subgroups $(R R=1.65)$ all had $R R$ values close to or higher than the summery results $(R R=1.63)$ (Table 3$)$.

\section{Publication bias}

The funnel plot analysis was performed on the included studies with the efficiency as the index. The results showed that the scattered points were distributed on both sides of the line and were close to the top of the funnel. The distribution was almost symmetric (Figure 7). The results indicate that there is little possibility of publication bias.

\section{Discussion}

Since the clinical application of Endostar, combined treatment with Endostar and platinum has been widely used in malignant serous effusions, achieving satisfactory results. However, due to little sample size and inconsistency in research design, interventions measures and observation index, there are many inconclusive problems on Endostar combined with platinum MSE therapy about dose, treatment interval and period, curative effect and adverse reactions. This study performed comprehensive quantitative analysis to explore the value of Endostar in the treatment of MSE.

A total of 25 RCTs were included in this study, with 749 cases in the experimental group and 774 cases in the control group. Meta-analysis showed that Endostar combined with platinum group has higher response rate (76\%) than platinum single drug group (47\%) (1.63 fold, $P<0.00001)$ and higher quality of life improvement rate $(69 \%)$ than platinum single drug grouop (44\%) $(1.57$ fold, $P<0.00001)$. This indicates that the effusions control efficiency and the patients' quality of life improvement was better than in experiment group than the control group. There was no significant difference between experiment group and control group in the incidence of nausea and vomiting (35\% vs. 34\%), white blood cell reduction (38\% vs. $38 \%$ ) and renal function damage (18\% vs. 20\%) $(P>0.05)$. In a retrospective study of Ma Qian (Ma, 2014) including 43 cases of malignant hydrothorax and ascites patients, the response rate of bevacizumab combined with cisplatin group was 1.66 times of the cisplatin group $(80 \%$ $v s .48 \%, P<0.05)$. Therefore, combinations of Endostar or bevacizumab with cisplatin are superior to cisplatin monotherapy in the therapeutic efficacy of MSE, with similar efficiency between Endostar and bevacizumab. However, Endostar is more readily available and cheaper than bevacizumab in clinical practice, and is worth of clinical application.

There is no unified standard in Platinum drug type combined with Endostar, optimal dose, optimal treatment interval and duration of Endostar in the treatment of MSE. This study investigated these questions respectively. In included studies, combined Endostar and platinum group (Endostar dose: $30-60 \mathrm{mg} /$ time) can achieve 53-83\% response rates in MSE, with highest RR value in $45 \mathrm{mg}$ dose group (6 RCTs, $\mathrm{RR}=1.76$ ), second highest $\mathrm{RR}$ value in $30 \mathrm{mg}$ dose group (5 RCTs, $\mathrm{RR}=1.7$ ), and third highest $\mathrm{RR}$ value in $60 \mathrm{mg}$ dose group ( $8 \mathrm{RCTs}, \mathrm{RR}=1.62$ ). The $\mathrm{RR}$ values of $30 \mathrm{mg}$ dose group and $45 \mathrm{mg}$ dose group were slightly higher than the aggregate results (1.63), but no obvious dose effect relationship was found among these data. This suggests that Endostar ar $45 \mathrm{mg} /$ time may be the most appropriate dose. A single large dose of Endostar is rare in clinical practice. In our results only 2 studies were included with single dose of Endostar more than $90 \mathrm{mg} /$ time, with no significant increase in response rate ( $R R=1.51)$, so is not recommended routinely. Compared with the $R R$ value of pooled results $(R R=1.63)$, $R R$ value with treatment interval of 3 days ( $3 R C T, R R=1.51$ ) was significantly decreased and RR value with treatment interval of 1 week (19 RCT, RR=1.67) was significantly increased. Therefore Endostar treatment interval of 1 week is usually recommended in clinical practice. $R R$ value in treatment time $\leq 2$ weeks ( $6 \mathrm{RCTs}, \mathrm{RR}=1.58$ ) was similar to that in treatment time $>2$ weeks (Most study was 4 weeks, 13 RCTs, $R R=1.61$ ). This indicates that treatment time length may have no significant effect on response rate, and 2-4 weeks is appropriate and is usually recommended, adjusted based on severity of illness, tolerance and the compliance of the individuals. The RR value of Endostar combined with cisplatin ( $22 \mathrm{RCTs}, \mathrm{RR}=1.65)$ was similar to that of summary results ( $25 \mathrm{RCTs}, \mathrm{RR}=1.63$ ). The therapeutic effect of Endostar combined with second generation platinum (2 RCTs combined with nedaplatin, 1 RCT combined with carboplatin) does not seem to be superior to that of cisplatin, therefore in clinical, cisplatin treatment is preferred due to lower costs and adverse reactions similar to second generation platinum.

There are some limitations in this study: 1 The majority of the literatures only referred to the random words, and the specific random methods was not described, so the random method may not be sufficient. 2 All RCTs did not describe the allocation concealment and blind method, which may lead to the bias in intervention implementation or the outcome measure, thereby reducing the reliability of the results. 3 The inconsistency in treatment dosage and time of platinum and Endostar may affect the outcome. 4 Tumor location in included patients was not completely consistent, and the initial treatment and retreatment conditions of effusion patients was not clear, so stratified analysis can not be applied in the measured observation index. 5 Most of the trials did not perform follow-up, and were terminated when the therapeutic effects were observed, so it is lack of long-term efficacy such as duration of efficacy and overall survival data. We hope the future clinical research can further improve the quality of method, especially the implementation of random scheme and blind method, and also can optimize the above test methods and experiment design.

\section{References}

Barni S, Cabiddu M, Ghilardi M, et al (2011). A novel perspective for an orphan problem: old and new drugs for the medical management of malignant ascites. Crit Rev Oncol Hematol, 79, 144-53. 
Becker G, Galandi D, Blum HE (2006). Malignant ascites: systematic review and guideline for treatment. Eur J Cancer, 42, 589-97.

Fan J, DU J, Wu J, et al (2015). Antitumor effects of different administration sequences of cisplatin and Endostar on Lewis lung carcinoma. Oncol Lett, 9, 822-8.

Fei ZH, Yang XL (2011). Observation of clinical efficacy of endostar combined with cisplatin in the treatment for 32 cases of malignant ascite/pleural effusion patients. Zheiiane Practical Methane, 4, 266-7.

Hang LM, Yu XL, Song H (2011). A comparision of between clinical efficacy intrapleural injection of cisplatin combined with Human recombinant endostatin and cisplatin alone in the treatment for malignant serous effusion. Chinese $J$ Geriatric Care, 2, 44-5.

Hang ZC, Wang F, Liu J (2013). The effect of rhendostatin combined with cisplatinum on patients with malignant pleural effusion. Chinese J Clin Pharmacol, 29, 587-9.

Huang J (2010). Observation of clinical efficacy of endostar combined with cisplatin in the treatment of malignant pleural effusion. J Clin Med Practice, 14, 63-4.

Huang L (2014). Clinical observation on endostar combined cisplatin in the treatment of non-small cell lung cancer malignant pleural effusion. Jilin Med, 19, 4308-9.

Jiang B (2012). Clinical trials of endostar combined cisplatin for the local treatment of malignant pleural effusion. Qinghai University.

Kang LY, Gao LM, Chao JL, et al (2013). Clinical observation on recombinant human endostain combined with cisplatinum intracavitary perfusion chemotherapy for malignant pleural effusion. Clinical Focus, 28, 1371-3.

Kobold S, Hegewisch-Becker S, Oechsle K, et al (2009). Intraperitoneal VEGF inhibition using bevacizumab: a potential approach for the symptomatic treatment of malignant ascites? Oncologist, 14, 1242-51.

Li JP, Gong KT, Zhu ZT, et al (2010). Recombinant human endostatin combined with cisplatin for malignant pleural effusion: a clinical study. China Pharmacy, 14, 1308-10.

Li W, Ha MW, Ying NC, et al (2010). A clinical study of endostar combined with cisplatin intrapleural perfusion chemotherapy for non-small cell lung cancer with malignant pleural effusion. Shandong Med J, 8, 79-80.

Li WY (2010). Observation of clinical efficacy of endostar intracavitary perfusion chemotherapy for malignant pleural effusion. J Med Forum, 32, 170-1.

Ling Y, Yang Y, Lu N, et al (2007). Endostar, a novel recombinant human endostatin, exerts antiangiogenic effect via blocking VEGF-induced tyrosine phosphorylation of KDR/Flk-1 of endothelial cells. Biochem Biophys Res Commun, 361, 79-84.

Liu J, Ye $P$, Su Z, et al (2015). Suppression of choroidal neovascularization by Endostar in rats. Mol Med Rep, 11, $3621-5$.

Liu X, Wang LP (2012). Clinical observation of intracavitary chemotherapy of endostar combined with chemotherapy in the treatment of non-small cell lung cancer with malignant pleural effusion. J Basic Clin Oncol, 25, 233-5.

Liu ZC, Cui EH, Wang B, et al (2011). Observation of clinical efficacy of human recombinant endostatin combined with carboplatin in the treatment for malignant pleural effusion. Zhejiang J Integrated Traditional Chinese Western Med, 11, 784-5.

Lu HL (2014). Clinical observation on human recombinant endostatin combined with chemotherapy in the treatment of pleural effusion. Med Frontier, 14, 396-6.

Lu N, Ling Y, Gao Y, et al (2008). Endostar suppresses invasion through downregulating the expression of matrix metalloproteinase-2/9 in MDA-MB-435 human breast cancer cells. Exp Biol Med (Maywood), 233, 1013-20.

Ma Q (2014). Intrapleural and intraperitoneal combination therapy with bevacizumab and cisplatin for malignant pleural effusion and ascites. Dalian Medical University.

Mao LW, Liao GQ, Wang HM, et al (2011). Observation of clinical efficacy of endostar combined with DDP on malignant bloody pleural effusion. Med J National Defending Forces Southwest China, 21, 723-5.

Miao H, Kong FJ (2012). Clinical observation on radiofrequency thermotherapy combined with endostar and cisplatin in the treatment of malignant pleural effusion. Chinese Community Doctors, 14, 86-7.

Shen Q, Gu AQ, Wu JY, et al (2012). Therapeutic observation of endostar combined with cisplatin on non-small cell lung cancer with malignant pleural effusion. J Clin Med Practice, 5, 29-31.

Tamsma J (2007). The pathogenesis of malignant ascites. Cancer Treat Res, 134, 109-18.

Verheul HM, Hoekman K, Jorna AS, et al (2000). Targeting vascular endothelial growth factor blockade: ascites and pleural effusion formation. Oncologist, 5, 45-50.

Wei H, Qin S, Yin X, et al (2015). Endostar inhibits ascites formation and prolongs survival in mouse models of malignant ascites. Oncol Lett, 9, 2694-700.

Wu Y, Zheng Y, Shen Z, et al (2014). Endostar combined with radiotherapy increases radiation sensitivity by decreasing the expression of TGF- $\beta 1$, HIF- $1 \alpha$ and bFGF. Exp Ther Med, 7, 911-6.

Xiao F, Xiao ML, Tang YB, et al (2014). Clinical research on rhendostatin combined with cis-platinum on patients with maliganant peritoneal effusion. Chinese Foreign Health Abstract, 15, 43-4.

Xu M, Huang H, Xiong Y, et al (2014). Combined chemotherapy plus endostar with sequential stereotactic radiotherapy as salvage treatment for recurrent esophageal cancer with severe dyspnea: A case report and review of the literature. Oncol Lett, 8, 291-4.

Xue H (2012). Clinical research on recombinant human endostain in the treatment of malignant ascite/pleural effusion. Chinese Community Doctors, 14, 82 .

Yan J, Jiang Y, Xu HL (2012). The research progress of endostar in the treatment of malignant Ascite/pleural effusion. Practical J Cancer, 5, 538-9.

Yang K (2013). Clinical study of recombinant human endostatin combined with nadaplatin for treatment of malignant pleural effusion. Acta Academiae Medicinae Xuzhou, 33, 891-3.

Yang Y, Lin TY, Chao GM (2013). Shortterm and longterm efficacy of endostar combined with cisplatinum malignant pleural effusion of non-small cell lung cancer. China Pharmaceuticals, 22, 21-2.

Yao QH, Lin QF, Liu SP, et al (2012). Efficacy of intrapleural infusion of endostar combined with nedaplatin in the treatment of malignant pleural effusion. $J$ Basic Clinical Oncol, 25, 492-4.

Yue GJ, Bo YJ, Ma H, et al (2014). Analysis of efficacy and security on endostar combined with cisplatin in the treatment of nonsmall cell lung cancer bloody pleural effusion. Modern Diagnosis Treatment, 11, 2478-80.

Zhao WY, Chen DY, Chen JH, et al (2014). Effects of intracavitary administration of endostar combined with cisplatin in malignant pleural effusion and ascites. Cell Biochem Biophys, 70, 623-8.

Zhen LP, Xia LP, Xu TF, et al (2011). Cinical efficacy of DDP combined endostar by sequential perfusion and effect on VEGF expression in malignant ascite/pleural effusion. Practical Preventive Mxlicine, 8, 1494-6. 
Rong Liang et al

Zhen QH, Hu W, Liao XF, et al (2013). A comparision between intrapleural injection of cisplatin combined with endostar and cisplatin alone in the treatment for malignant pleural effusion. J Chinese Oncol, 5, 386-9.

Zhou WB, Bai M, Jin Y (2009). Diagnostic value of vascular endothelial growth factor and endostatin in malignant pleural effusions. Int J Tuberc Lung Dis, 13, 381-6. 